\title{
Evaluation of ram semen motility by a swim-up technique
}

\author{
P. Suttiyotin* and C. J. Thwaites \\ Department of Animal Science, University of New England, NSW 2351, Australia
}

\begin{abstract}
The turbidity formed as ram spermatozoa swam up into a clear medium was measured using a colorimeter and this was used as an objective index of sperm motility. Wavelengths of $470-475 \mathrm{~nm}$ yielded higher optical densities (OD) than did $520-640 \mathrm{~nm}$. The recommended distance between the light beam and semen-medium interface, and operation temperature were $5 \mathrm{~mm}$ and $30-37^{\circ} \mathrm{C}$, respectively. Of seven media tested, Tris-glucose was preferred on the basis of results, availability and cost. Diluting semen before testing reduced OD, whereas increasing semen concentration ( 0.6 to $2.4 \times 10^{9}$ spermatozoa $\left.\mathrm{ml}^{-1}\right)$ and the total number of spermatozoa used increased OD. OD gradually increased with time in all experiments $(P<0.001)$. High positive correlations between $\mathrm{OD}$ and known percentages of motile spermatozoa $(0.82-0.91$ at from 5 to $20 \mathrm{~min}$, all $P<0.001)$ suggest that this swim-up technique, which is objective and inexpensive, is valid for measurement of sperm motility in rams.
\end{abstract}

\section{Introduction}

Visual assessment of sperm motility is simple, rapid and inexpensive, but its subjective nature leads to variation between observers and over time. A number of objective methods of assessing motility have been developed (Rothschild, 1948, 1953a, b; Dott, 1975), but are time consuming and relatively expensive. Sokoloski et al. (1977) proposed changes in optical density (OD) as a means of estimating the velocity of spermatozoa swimming into a medium, and this basic approach led us to develop an alternative procedure which we refer to as a swim-up technique.

This paper reports on experiments designed to investigate factors that could be expected to affect the rate of OD increase as spermatozoa swim into a medium: wavelength, temperature, media, the presence of seminal plasma, semen dilution, semen concentration, and number of spermatozoa present. The potential of the method as an objective measure of semen motility was assessed by making observations on a series of semen samples containing known proportions of motile and immotile spermatozoa.

\section{Materials and Methods}

\section{Semen}

Semen from adult Merino rams with initial motility (Salamon, 1976) of at least $90 \%$ was normally diluted with $300 \mathrm{mmol}$ Tris $1^{-1}-28 \mathrm{mmol}$ glucose $\mathrm{l}^{-1}$ (TG) to $2 \times 10^{9}$ spermatozoa $\mathrm{ml}^{-1}$ and held at $37^{\circ} \mathrm{C}$. The percentage of progressively motile spermatozoa was estimated in a layer of diluted semen $60 \mu \mathrm{l}$ thick at $\times 150$ and $37^{\circ} \mathrm{C}$.

*Present address: Department of Animal Sciences, Faculty of Natural Resources, Prince of Sangkla University, Hat Yai, Songkhla 90110, Thailand. Received 24 February 1992.

\section{Cuvettes and colorimeter}

Semen was layered at the bottom of modified, disposable cuvettes (Suttiyotin and Thwaites, 1992) and OD readings were routinely made at $5 \mathrm{~min}$, or as otherwise indicated; the cuvettes and colorimeter were maintained at $37^{\circ} \mathrm{C}$. The absorption spectra of seminal plasma, Tris-glucose and semen diluted with TG was established by using an automatic spectrophotometer fitted with a sample sipper and data plotter.

\section{Media}

Seven well-known media were studied: (i) Krebs Ringer bicarbonate with $0.2 \% \mathrm{BSA}$ (K1: prepared in the laboratory, 323 mosmol, pH 7.4; K2: Sigma Chemical Co., Sydney; 267 mosmol, $\mathrm{pH} 7.0$ ), (ii) ova maintenance medium (OMM: CSL, Melbourne, 306 mosmol, pH 7.0), (iii) Ham's F-10 (HAM: ICN Flow, Sydney, 250 mosmol, pH 7.0); (iv) modified Tyrode's solution (MT: Stewart-Savage and Bavister, 1988; $315 \mathrm{mosmol}$, pH 7.0); (v) BWW (Biggers et al., 1971; 308 mosmol, pH 7.0), (vi) Tris-glucose (TG, $328 \mathrm{mosmol}, \mathrm{pH} 7.0$ ); and (vii) Trisfructose (TF, 356 mosmol, pH 7.0: both after Salamon and Visser, 1972).

\section{Wavelength}

Latin-square designs were used to study $O D$ changes in semen diluted $1: 1$ with $\mathrm{K} 1$ at 490,520 and $540 \mathrm{~nm}$. A flow through cuvette (Sokoloski et al., 1977) was used and readings were made every $10 \mathrm{~s}$ for $5 \mathrm{~min}$. Undiluted semen was also observed at $470,490,520$ and $540 \mathrm{~nm}$ using TG medium. The absorption spectra of semen diluted with TG $(25,75$ and $150 \times 10^{6}$ spermatozoa $\mathrm{ml}^{-1}$ ) and TG alone were established at from 190 to $900 \mathrm{~nm}$.

The absorption spectra of seminal plasma was similariy examined, using two replicates, in each of which two ejaculates 
from each of five rams were pooled and centrifuged at $2000 \mathrm{~g}$ for $15 \mathrm{~min}$. The supernatant was recentrifuged until examination by microscope revealed that the seminal plasma contained no spermatozoa. Spermatozoa obtained from the sediment after centrifugation were then washed three times in TG before being resuspended in TG to yield a suspension of $25 \times 10^{6}$ spermatozoa $\mathrm{ml}^{-1}$ which was scanned for absorption as before.

\section{Distance from semen-medium interface to light beam}

OD was measured after adjusting the distance between the lower edge of the light beam and the semen-medium interface to $1,3,5,7$ or $9 \mathrm{~mm}$ by means of a vernier cuvette support attached to the colorimeter (Suttiyotin and Thwaites, 1992).

\section{Temperatures}

Semen from each of four rams was diluted and allowed to swim up into TG at either $5,10,20,30$ or $37^{\circ} \mathrm{C}$ and OD was recorded.

\section{Media}

Comparisons of the efficacies of $\mathrm{KI}, \mathrm{OMM}, \mathrm{TG}$ and $\mathrm{TF}$ (undiluted semen), of K2, OMM, TG and TF (undiluted semen), and of HAM, MT, BWW and TG (diluted semen) were made at $470 \mathrm{~nm}$. The possible effects of glucose in the medium were investigated by allowing four replicate subsamples of undiluted semen from four ejaculates to swim up into Tris solutions $\left(300 \mathrm{mmol} \mathrm{1}^{-1}\right)$ supplemented with $0,0.05,0.1,0.5$ and $1 \%$ glucose.

\section{Seminal plasma}

On three separate occasions, ejaculates from two rams were pooled and centrifuged at $600 \mathrm{~g}$ for $15 \mathrm{~min}$ before supernatant and spermatozoa were separated. The seminal plasma was prepared by recentrifuging the supernatant at $2000 \mathrm{~g}$ for a further $15 \mathrm{~min}$ and discarding the sediment. The sperm pellet was resuspended in TG to the original volume and divided into two aliquots, one of which served as a motile sperm suspension (control) while the other was shocked in an $80^{\circ} \mathrm{C}$ water bath for $15 \mathrm{~min}$ and served as an immotile (absence of progressive motility confirmed using a microscope) sperm suspension. OD was measured using seminal plasma and both the motile and immotile sperm suspensions.

\section{Semen dilution}

The semen from three rams was used either undiluted or diluted 1:1, 1:2 or 1:3 with TG. The number of spermatozoa in each treatment was standardized by using respective volumes of $0.05,0.10,0.15$ and $0.20 \mathrm{ml}$. The possible effects of different concentrations of seminal plasma in diluted semen under study were examined in suspensions of $2 \times 10^{9}$ spermatozoa ml ${ }^{-1}$ in TG or seminal plasma alone, or with 10 or $20 \%$ seminal plasma in TG. Four replicate subsamples from each semen suspension were used in each of three replicates.

\section{Semen concentration}

Pooled ejaculates from two rams were diluted with TG to 2.4, 1.2, 0.8 and $0.6 \times 10^{9}$ spermatozoa $\mathrm{ml}^{-1}$ and aliquots containing $120 \times 10^{6}$ spermatozoa $(50,100,150$ and $200 \mu \mathrm{l}$, respectively) were tested in each of four replicates. Perspex blocks of different thicknesses were placed under the cuvettes to standardize the distance between the semen-medium interface and the lower edge of the colorimeter light beam at $5 \mathrm{~mm}$.

\section{Total number of spermatozoa}

Ejaculates from each of four rams were diluted with TG to $1 \times 10^{9}$ spermatozoa $\mathrm{ml}^{-1}$ and four replicated subsamples containing $50,100,150$ or $200 \times 10^{6}$ spermatozoa were tested.

\section{Correlation with known percentage of motile spermatozoa}

Pooled semen from four rams was centrifuged, washed with TG and frozen-thawed a number of times until examination by microscope $(x 150)$ revealed no motility. The spermatozoa were then rewashed and suspended in TG at $2 \times 10^{9}$ spermatozoa $\mathrm{ml}^{-1}$ to form an 'immotile' cell suspension (Suttiyotin and Thwaites, 1991). A 'motile' cell suspension was formed by diluting fresh semen from four other rams to $2 \times 10^{9}$ spermatozoa $\mathrm{ml}^{-1}$ with TG and subjectively assessing the progressive motility (mean 97.5\%). Four replicate test samples (200 $\times 10^{6}$ spermatozoa) containing known percentages of 'motile' cells were prepared by mixing the 'immotile' and 'motile' cell suspensions in the ratios 1:0, 3:1, 1:1, 1:3 and $0: 1$.

\section{Loss of motility during the swim-up procedure}

The extent of loss of sperm motility was checked during the 20 min required for swim-up assessment by evaluating samples from two sources for progressive motility using a microscope. First, in several of the preceding experiments, progressive motility was checked before loading into the cuvette, and again after mixing the contents of the cuvettes after a 20 min test. Second, a dummy run of the swim-up procedure was conducted, using four pooled semen samples, three replicate cuvettes per time, and three observers. Duplicates of each semen sample, as loaded into the cuvettes, were held in three small test tubes at $37^{\circ} \mathrm{C}$ as controls. Subsamples were withdrawn from the bottom of the cuvettes and the corresponding test tubes at $0,5,10,15$ or $20 \mathrm{~min}$ after loading of the semen and the percentage of progressive motility was estimated by three observers at the same time using a projecting microscope $(\times 125)$.

\section{Statistical analysis}

The data, after appropriate angular transformation, were analysed by a computer programmed analysis of variance for repeated measures. Where a significant difference between means was observed, it was tested by Duncan's new multiple range test (Steel and Torrie, 1980) and linear regression analysis was used to relate the known percentage of motile spermatozoa in a test suspension to OD when applicable. 
Table 1. Means of optical density readings of diluted semen (spermatozoa, seminal plasma and TG), seminal plasma alone and spermatozoa diluted in TG (no seminal plasma)

\begin{tabular}{lccc}
\hline $\begin{array}{l}\text { Wavelength } \\
(\mathrm{nm})\end{array}$ & $\begin{array}{c}\text { Diluted } \\
\text { semen }\end{array}$ & Plasma & $\begin{array}{c}\text { Spermatozoa } \\
+\mathrm{TG}\end{array}$ \\
\hline 640 & $1.70 \pm 0.23^{\mathrm{a}}$ & $0.38 \pm 0.10^{\mathrm{a}}$ & $1.37 \pm 0.19^{\mathrm{a}}$ \\
610 & $1.71 \pm 0.23^{\mathrm{a}}$ & $0.43 \pm 0.08^{\mathrm{ab}}$ & $1.39 \pm 0.19^{\mathrm{ab}}$ \\
578 & $1.72 \pm 0.23^{\mathrm{a}}$ & $0.50 \pm 0.09^{\mathrm{b}}$ & $1.41 \pm 0.19^{\mathrm{b}}$ \\
520 & $1.76 \pm 0.23^{\mathrm{b}}$ & $0.67 \pm 0.11^{\mathrm{c}}$ & $1.47 \pm 0.19^{\mathrm{c}}$ \\
475 & $1.84 \pm 0.22^{\mathrm{c}}$ & $0.89 \pm 0.14^{\mathrm{d}}$ & $1.54 \pm 0.19^{\mathrm{d}}$ \\
440 & $1.91 \pm 0.22^{\mathrm{d}}$ & $1.69 \pm 0.19^{\mathrm{e}}$ & $1.73 \pm 0.19^{\mathrm{e}}$ \\
400 & & & \\
\hline
\end{tabular}

TG: $300 \mathrm{mmol}$ Tris $\mathrm{l}^{-1}-28 \mathrm{mmol}$ glucose $\mathrm{l}^{-1}$.

Values are means \pm SEM.

Means within columns with different superscripts differ significantly $(P<0.05)$.

\section{Results}

\section{Wavelength}

Differences in OD between wavelengths were not significant $(0.07-0.08$ in diluted semen at $490-540 \mathrm{~nm}$ and $0.49-0.50$ in undiluted semen at $470-540 \mathrm{~nm}$ ). Neither TG nor semen diluted with TG showed any distinctive absorption peaks within the visible range of 400 to $700 \mathrm{~nm}$. For semen diluted with TG, OD increased from 1.70 at $640 \mathrm{~nm}$ to 1.91 at $440 \mathrm{~nm}$ (Table 1). Below $400 \mathrm{~nm}$, the OD of both TG and semen diluted with TG increased dramatically to values $>3.0$. Seminal plasma and the suspension of spermatozoa in TG yielded similar spectra to diluted semen and in both cases $O D$ increased as wavelength was reduced from 640 to $578 \mathrm{~nm}$ (Table 1).

\section{Distance from semen-medium interface to light beam}

Distances of 1 and $3 \mathrm{~mm}$ yielded OD values of $1.10-1.38$ during the 20 min test. At $5 \mathrm{~mm}$, OD increased progressively to reach a plateau value of 0.78 after $10 \mathrm{~min}$, whereas at 7 and $9 \mathrm{~mm}$ the rate of OD increase was much less. After $5 \mathrm{~min}$, $O D$ at $5 \mathrm{~mm}(0.35 \pm 0.13)$ was higher than at 7 and $9 \mathrm{~mm}$ $(0.12 \pm 0.07$ and $0.17 \pm 0.01$, respectively, $P<0.05)$.

\section{Temperature}

At $20-37^{\circ} \mathrm{C}$, OD increased progressively with time, but at 5 and $10^{\circ} \mathrm{C}$, values were constant and low $(0.01-0.09)$. The overall $\mathrm{OD}$ at $37^{\circ} \mathrm{C}(0.78 \pm 0.07)$ was lower than at $30^{\circ} \mathrm{C}$ $\{0.82 \pm 0.07, P<0.05)$ but higher than at $20^{\circ} \mathrm{C}(0.30 \pm 0.06$, $P<0.001)$.

\section{Media}

$O D$ readings using $O M M$ and TF were not significantly different $(0.54 \pm 0.05$ and $0.60 \pm 0.03$, respectively), but both were lower than in TG $(0.78 \pm 0.02, P<0.001$ and $P<0.01$, respectively) and higher than in $\mathrm{K} 1(0.10 \pm 0.01, P<0.001)$.

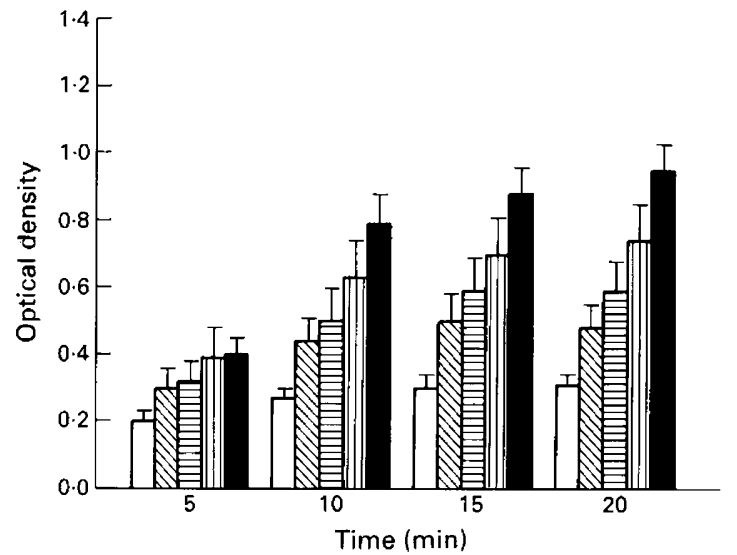

Fig. 1. Optical density of ram spermatozoa during swim up in Tris medium containing ( $\square$ ) 0 , (田) 0.05 , (目) 0.10 , (而) 0.50 and ( $1.00 \%$ glucose.

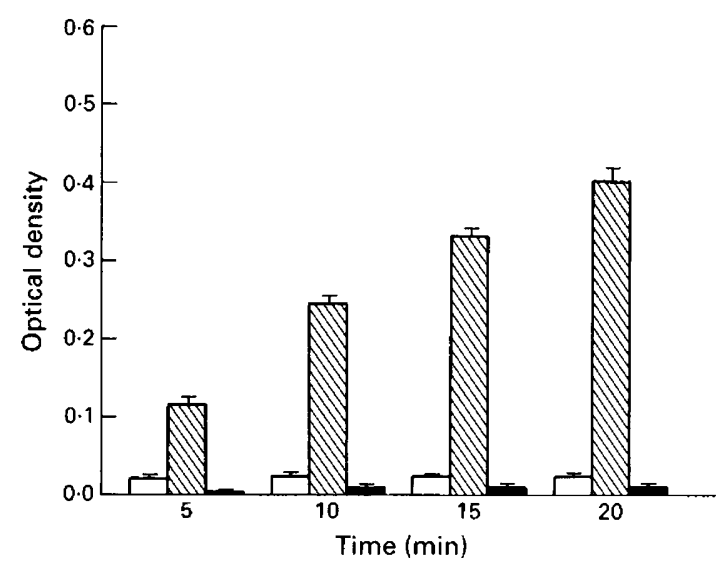

Fig. 2. Optical density of ( $\square$ ) seminal plasma and ( $\mathbf{N}$ ) motile and ( immotile cell suspensions in the swim-up technique.

OD readings using $\mathrm{K} 2$ and $\mathrm{OMM}$ did not differ significantly $(0.39 \pm 0.04$ and $0.43 \pm 0.05$, respectively), but those for $\mathrm{K} 2$ were lower than for both TF $(0.41 \pm 0.02, P<0.005)$ and TG $(0.47 \pm 0.03, P<0.001)$. BWW yielded lower OD $(0.19 \pm 0.02)$ than MT, HAM and TG $(0.22 \pm 0.02$, $0.26 \pm 0.02$ and $0.28 \pm 0.02$, respectively, $P<0.05$ ).

The presence of glucose in Tris medium produced greater OD responses than Tris medium alone (Fig. $1, P<0.001$ ). OD progressively increased with increasing glucose concentrations $(P<0.005)$.

\section{Seminal plasma}

Seminal plasma and the immotile sperm suspension produced similar OD values (Fig. 2), both of which were lower than for the motile spermatozoa suspension $(P<0.001)$.

\section{Semen dilution}

The mean $O D$ values recorded when ram semen was diluted $1: 1,1: 2$ or $1: 3$ with TG $(0.33 \pm 0.02,0.32 \pm 0.02$ and Downloaded from Bioscientifica.com at 04/26/2023 11:14:13AM 

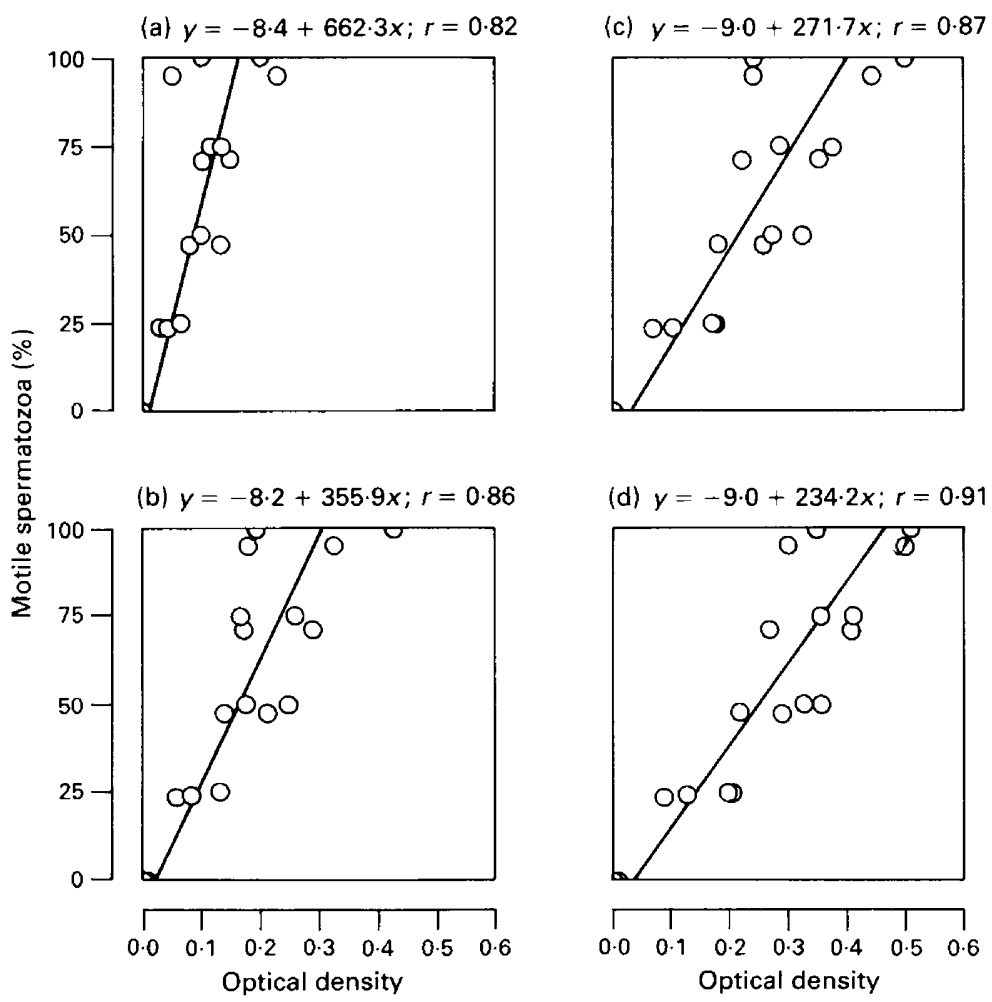

(d) $y=-9 \cdot 0+234 \cdot 2 x ; r=0.91$

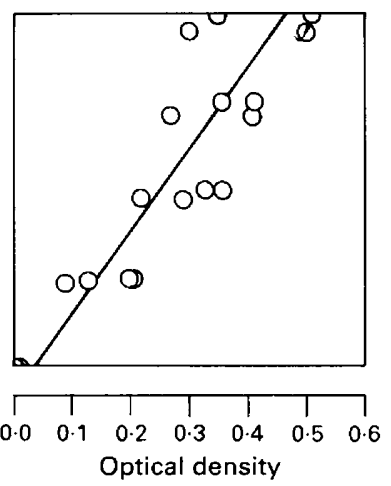

Fig. 3. Relationships between known proportions of motile and immotile spermatozoa and optical density readings at (a) $5 \mathrm{~min}$, (b) $10 \mathrm{~min}$, (c) $15 \mathrm{~min}$ and (d) $20 \mathrm{~min}$.

$0.32 \pm 0.02$, respectively, n.s.) were less than for undiluted semen $\{0.49 \pm 0.03, P<0.001)$. Increasing the seminal plasma concentration increased OD: although the mean OD of samples containing 0 and $10 \%$ plasma did not differ $(0.38 \pm 0.02$ and $0.40 \pm 0.02$, respectively), those for 20 and $100 \%$ plasma were increased $(0.46 \pm 0.03$ and $0.54 \pm 0.02$, respectively, $P<0.001)$.

\section{Semen concentration}

OD gradually increased with increasing semen concentration; although $\mathrm{OD}$ at 0.6 and $0.8 \times 10^{9}$ spermatozoa $\mathrm{ml}^{-1}$ did not differ $(0.40 \pm 0.03$ and $0.41 \pm 0.03$, respectively), both values were lower than that at $1.2(0.47 \pm 0.03, P<0.05)$ and $2.4 \times 10^{9}$ spermatozoa ml ${ }^{-1}(0.59 \pm 0.03, P<0.001)$.

\section{Total number of spermatozoa}

The number of spermatozoa deposited had a positive effect on $\mathrm{OD}$; mean values were $0.21 \pm 0.01,0.37 \pm 0.03$, $0.57 \pm 0.04$ and $0.74 \pm 0.04$ for $50,100,150$ and $200 \times 10^{9}$ spermatozoa, respectively (all $P<0.001$ ).

\section{Correlation with known percentage of motile spermatozoa}

Regression analyses revealed that the correlations between the proportion of motile spermatozoa and OD at each time point were homogeneous and the data were thus pooled for each time and re-analysed. The resultant correlations between the percentage of motile spermatozoa and $\mathrm{OD}$ at $5,10,15$ and $20 \mathrm{~min}$ were $0.82,0.86,0.87$ and 0.91 , respectively (all $P<0.001$ ). The relationships between these variables are presented (Fig. 3) and the application of Bartlett's test (Snedecor and Cochran, 1967) revealed that the variances within times were not significant.

\section{Loss of motility}

Motility loss during $20 \mathrm{~min}$ of the swim-up procedure in the preceding experiments ranged from 9.7 to $20.0 \%$ except for KI $(59 \%)$. In the dummy run of the technique, the percentages of motility lost at 5, 10, 15 and 20 min were not significantly different $(8.2 \pm 2.7,6.2 \pm 1.8,4.9 \pm 2.0$ and $4.0 \pm 1.6$, respectively). There were no significant differences between either ejaculates or observers. However, the percentage of motility lost was lower in the test tubes $(1.2 \pm 1.4)$ than in the cuvettes $(10.4 \pm 1.4, P<0.001)$.

In all experiments OD increased with time $(P<0.001)$.

\section{Discussion}

The ability of spermatozoa to swim up into a medium has been used extensively in the selection of motile cells (Lopata et al., 1976; Berger et al., 1985; Tanphaichitr et al., 1987) for in vitro fertilization. The same principle was later used to evaluate sperm motility (Sokoloski et al., 1977; Levin et al., 1980, 1981, 
1984) by measuring turbidity of the medium as spermatozoa swam into it.

The wavelengths used by earlier workers ranged from 475 (Atherton et al., 1978) to 545 (Sokoloski et al., 1977; Majumder and Chakrabarti, 1984; Sidhu and Guraya, 1990), 550 (Jasko et al., 1989) and $580 \mathrm{~nm}$ (Deana et al., 1986). As a general rule, accuracy and sensitivity will be greatest if the wavelength used yields maximum OD and corresponds to any specific absorption peaks (Skoog, 1985). Optimum wavelengths were determined by scanning samples across an appropriate range. In the swim-up technique, OD necessarily changes with time and normal scanning is thus not possible. Three alternative approaches were used in the work reported here. First, measurements at fixed times failed to detect any difference in OD with the four colorimeter filters used, which had, however, a bandpass of $40 \mathrm{~nm}$ which may have masked small variations in OD. However, no specific absorption peaks in the visible light range were seen in the spectrophotometer scans. In contrast, strong absorption peaks (OD $>3.0$ ) were observed in the ultraviolet (UV) range (190-400 $\mathrm{nm}$ ).

Atherton et al. (1978) scanned human seminal plasma and reported significant interference from seminal plasma and debris in the UV range. To minimize such effects, they suggested the use of a wavelength of $475 \mathrm{~nm}$. Similar effects of seminal plasma were observed in the study reported here; interference was lower at $640 \mathrm{~nm}$ than at $610,578,520$ or $475 \mathrm{~nm}$. The absorption spectrum of ram seminal plasma observed in the present study was similar to that reported by Dott (1974) for the bull. Although high wavelengths minimize interference from seminal plasma, they concurrently reduce $O D$ readings and thus lower accuracy. In contrast, low wavelengths yield higher OD readings, but are subject to interference. However, the current work indicates that neither seminal plasma nor immotile spermatozoa increased $\mathrm{OD}$ in the swim-up technique and the use of $475 \mathrm{~nm}$ is recommended. At $475 \mathrm{~nm}$ high OD readings are obtained and this wavelength corresponds to that used by Atherton et al. (1978) for human semen and to the 'blue' filters recommended for colorimetric evaluation of ram semen by Emik and Sidwell (1947) and Salamon (1976). The increase in OD with increasing wavelength when scanning a suspension of spermatozoa in TG contrasts with a plateau spectra for TG alone and indicates that the increase in OD results from spermatozoa themselves.

The high initial OD readings when the distances of $I$ and $3 \mathrm{~mm}$ were used between the lower edge of the light beam and semen-medium interface suggest that these distances were too small to be practical. Each of the distances 5, 7 and $9 \mathrm{~mm}$ produced increasing OD over time, but $5 \mathrm{~mm}$ yielded the highest reading at $5 \mathrm{~min}$ and is thus preferred.

Temperatures of 5 and $10^{\circ} \mathrm{C}$ yielded only low $\mathrm{OD}$ values and are not suitable for this technique. However, temperatures of $30-37^{\circ} \mathrm{C}$ are recommended for use since they yielded higher $\mathrm{OD}$ than $20^{\circ} \mathrm{C}$ and correspond to those normally used in semen processing.

$\mathrm{KI}$ was inferior to OMM, TF and TG, possibly because it had a lower concentration of glucose. Although significant differences were observed in the efficacy of the media, mean differences in $\mathrm{OD}$ at $5 \mathrm{~min}$ (except for $\mathrm{K} 1$ ) were small $(0.08 \pm 0.03)$ and would not be expected to influence readings in the swim-up technique significantly. Apart from $\mathrm{K} 1$, the media were thus suitable for use. For ease of use, particularly in the field, Tris is both simple to prepare and store and supports sperm survival better than other buffered media studied (Davis et al., 1963; Gebauer et al., 1970) and glucose is cheap and widely available. As spermatozoa also tolerate a relatively wide range in concentration of Tris solution (Steinbach and Foote, 1967; Yassen and Foote, 1967; Igboeli, 1970; Salamon and Visser, 1972), TG was selected for routine use in the swim-up technique.

Neither immotile spermatozoa nor seminal plasma alone caused significant changes in OD (Fig. 2) and we thus conclude that the observed increases in $\mathrm{OD}$ in the swim-up technique are due to the upward movement of motile spermatozoa. This is consistent with the results of Sokoloski et al. (1977), who concluded that the settling speed of nonmotile cells was negligible compared with the swimming speed of motile cells.

A number of workers have reported that the dilution of semen reduces sperm motility (Cheng et al., 1949; Bavister, 1974) and fertility (Lapwood et al., 1972; Martin and Watson, 1973, 1976; Watson and Martin, 1976), although others have failed to distinguish any such effects (Jones et al., 1969; Entwistle and Martin, 1972). In the current work, a negative effect of dilution ( $1: 1$ to $1: 3$ ) on OD was clearly indicated, although the design initially used confounded the effects of dilution and semen concentration. This problem was subsequently rectified by standardizing the semen concentration; the results were consistent with earlier ones and indicated that $20 \%$ or more seminal plasma in the semen sample was beneficial in terms of the OD recorded. Seminal plasma is known to stimulate sperm motility (Lindholmer, 1974; Bavister and Yanagimachi, 1977; Bavister et al., 1978; Dott et al., 1979; Tso and Lee, 1980; Baas et al., 1983) and the current results indicate that using it as a diluent would increase OD values. However, preparation of seminal plasma is slow and costly, and its use would, in addition, possibly mask any deficiencies in the seminal plasma of the semen sample being tested. On balance, its use as the diluent in the swim-up technique is thus contra-indicated.

Our results indicate that semen concentration (number of spermatozoa available at the semen-medium interface) positively influenced OD. This is the first report of such an effect, and it supports the suggestion that the greater the number of spermatozoa available to swim up, the quicker the rise in OD and the higher the eventual values achieved. Although a high semen concentration would thus be desirable, compromise is necessary to take into account the range of semen concentrations encountered in the field. Most authorities (e.g. Salamon, 1976; Setchell, 1991) agree that $2 \times 10^{9}$ spermatozoa $\mathrm{ml}^{-1}$ represents the lower limit of normal semen concentration in rams. This value is thus recommended for routine use in the swim-up technique for rams; in most cases it will involve dilution only at a rate of between $1: 1$ and 1:2.

The number of spermatozoa available had a positive and marked effect on OD. After $20 \mathrm{~min}$, for example, OD for the $200 \times 10^{6}$ spermatozoa loading $(0.98 \pm 0.04)$ was more than three times higher than for $50 \times 10^{6}$ spermatozoa $(0.27 \pm$ 0.02 ). Such a response is in agreement with results of Deana et al. (1986), who found that the OD after $20 \mathrm{~min}$ varied from 0.4 to 0.9 with loadings of 0.05 and $0.15 \mathrm{ml}$ of bull semen (concentration not specified). Majumder and Chakrabarti (1984) reported a similar response in goat semen, although their semen loadings and OD values were much lower than those used in 
this study. Since the current work began, Jasko et al. (1989) have also reported a positive effect of sperm number on $O D$, although differences in technique make comparisons difficult. For routine use in the swim-up evaluation of ram semen, a sperm loading of $200 \times 10^{6}$ cells is recommended. The fact that variances within times did not differ significantly indicates that each of the times $(5-20 \mathrm{~min})$ studied yielded a similar level of accuracy. On the basis of the speed of operation and ease of reading the colorimeter, $5 \mathrm{~min}$ is recommended for the duration of the proposed swim-up technique. In addition, the negligible loss of motility for up to $20 \mathrm{~min}$ of the technique indicates that the conditions used (TG as a medium, $37^{\circ} \mathrm{C}$ ) were quite adequate to support spermatozoa. Had conditions been completely optimal, no differences in motility would have been expected between cuvettes and test tubes. In fact, semen in the cuvettes suffered, on average, a $9.2 \%$ greater motility loss than control samples in test tubes $(P<0.001)$. Loss of motile spermatozoa from the semen sample into the TG medium does not appear to have been a major contributor to the slight loss in motility observed, since differences with time were not significant.

Owing to failure to standardize the conditions under which swim-up type evaluations of sperm motility have been made in the past (Sokoloski et al., 1977; Majumder and Chakrabarti, 1984; Deana et al., 1986; Jasko et al., 1989; Sidhu and Guraya, 1990), it has not previously been possible to compare the results from different laboratories. The work reported here clearly demonstrates the need to standardize the wavelength and media used, the concentration and volume of semen loaded into the cuvette, the time allowed for each test, and the distance between the semenmedium interface and the light path through the colorimeter cuvette. In a number of colorimeters examined, the last distance varied from 8 to $15 \mathrm{~mm}$. For the swim-up technique, a standard distance of $5 \mathrm{~mm}$ is thus recommended, as it will accommodate most instruments, and can readily be achieved by placing an appropriate spacer block at the bottom of the cuvette well.

The following standard procedure for the swim-up technique is recommended: $0.1 \mathrm{ml}$ of semen previously diluted with TG to $2 \times 10^{9}$ spermatozoa $\mathrm{ml}^{-1}$ is layered at the bottom of a cuvette modified by the inclusion of an injection port and which contains $2 \mathrm{ml} \mathrm{TG}$. OD is then read at $470-475 \mathrm{~nm}$ after $5 \mathrm{~min}$; the distance between semen-medium interface and colorimeter light path is adjusted to $5 \mathrm{~mm}$, and the temperature standardized throughout at $30-37^{\circ} \mathrm{C}$.

This swim-up technique was shown to be valid in objectively evaluating semen motility as it was highly correlated with the known proportions of motile and immotile spermatozoa in the test samples, and with parameters from a Hamilton Thorn Motility Analyser (Suttiyotin et al., 1991; Suttiyotin and Thwaites, 1992).

The work was supported by the Thai-Australian Prince of Songkla University Project funded by the Australian International Development Assistance Bureau and grants from the University of New England. We thank N. Baillie, G. Chisholm and B. Johnston for technical assistance.

\section{References}

Atherton RW, Radany EW and Polakoski KL (1978) Spectrophotometric quantitation of mammalian spermatozoon motility. I. Human Biology of Reproduction 18 624-628
Baas JW, Molan PC and Shannon P (1983) Factors in seminal plasma of bulls that affect the viability and motility of spermatozoa Journal of Reproduction and Fertility 68 275-280

Bavister BD (1974) The effect of variations in culture conditions on motility of hamster spermatozoa Joumal of Reproduction and Fertility 38 431-440

Bavister BD and Yanagimachi R (1977) The effects of sperm extracts and energy sources on the motility and acrosome reaction of hamster spermatozoa in vitro Biology of Reproduction 16 228-237

Bavister BD, Rogers BJ and Yanagimachi R (1978) The effects of cauda epididymal plasma on the motility and acrosome reaction of hamster and guinea pig spermatozoa in vitro Biology of Reproduction 19 358-363

Berger T, Marrs RP and Moyer DL (1985) Comparison of techniques for selection of motile spermatozoa Fertility and Sterility $43268-273$

Biggers JD, Whitten WK and Whittingham DG (1971) The culture of mouse embryos in vitro. In Methods in Mammalian Embryology pp 86-116 Ed. JC Daniel. WH Freeman and Company, San Francisco

Cheng P, Casida LE and Barrett GR (1949) Effects of dilution on motility of bull spermatozoa and the relation between motility in high dilution and fertility Journal of Animal Science 8 81-88

Davis IS, Bratton RW and Foote RH (1963) Viability of bovine spermatozoa at 5 , -25 , and $-85^{\circ} \mathrm{C}$ in Tris-buffered and citrate-buffered yolk-glycerol extenders Joumal of Dairy Science 46 333-336

Deana R, Foresta C, Bonaga G. and Rigoni F (1986) A simple nephelometric method for measuring the progressive motility and collecting motile spermatozoa Andrologia 18 37-41

Dott HM (1974) The effects of bovine seminal plasma on the impedance change frequency and glycolysis of bovine epididymal spermatozoa Joumal of Reproduction and Fertility 38 147-156

Dott HM (1975) The estimation of the proportion of motile bull spermatozoa in various diluents and a comparison with the proportion eosinophilic Journal of Reproduction and Fertility 45 47-55

Dott HM, Harrison RAP and Foster GCA (1979) The maintenance of motility and the surface properties of epididymal spermatozoa from bull, rabbit and ram in homologous seminal and epididymal plasma Joumal of Reproduction and Fertility 55 113-124

Emik LO and Sidwell GM (1947) Factors affecting the estimation of concentration of sperm in ram's semen by the photoelectrometric method Journal of Animal Science 6 467-475

Entwistle KW and Martin ICA (1972) Effects of number of spermatozoa and of volume of diluted semen on fertility in the ewe Australian Journal of Agricultural Research 23 467-472

Gebauer MR, Pickett BW, Komarek RJ and Gaunya WS (1970) Motility of bovine spermatozoa extended in 'defined' diluents Journal of Dairy Science 53 $817-823$

Igboeli G (1970) A Tris-buffered egg yolk extender for boar semen Joumal of Animal Science 30 569-572

Jasko DJ, Smith K, Little TV, Lein D and Foote RH (1989) A spectrophotometric procedure for the determination of objective measurements of equine spermatozoan motility Theriogenology 31 945-954

Jones RC, Martin ICA and Lapwood KR (1969) Studies of the artificial insemination of sheep: the effects on fertility of diluting ram semen, stage of oestrus of the ewe at insemination, and injection of synthetic oxytocin Australian Joumal of Agricultural Research 20 141-150

Lapwood KR, Martin ICA and Entwistle KW (1972) The fertility of Merino ewes artificially inseminated with semen diluted in solutions based on skim milk, glucose, or ribose Australian Joumal of Agricultural Research 23 457-466

Levin RM, Shofer J and Greenberg SH (1980) A quantitative method for determining the effects of drugs on spermatozoal motility Fertility and Sterility 33 631-635

Levin RM, Greenberg SH and Wein AJ (1981) Clinical use of the turbidimetric analysis of sperm motility: comparison with visual techniques Fertility and Sterility $35 \quad 332-336$

Levin RM, Hypolite JA and Wein AJ (1984) Clinical use of the turbidimetric analysis of sperm motility: an update Andrologia 16 434-438

Lindholmer CH (1974) The importance of seminal plasma for human sperm motility Biology of Reproduction 10 533-542

Lopata A, Patullo MJ, Chang A and James B (1976) A method for collecting motile spermatozoa from human semen Fertility and Sterility $27677-684$

Majumder GC and Chakrabarti CK (1984) A simple spectrophotometric method of assay of forward motility of goat spermatozoa Journal of Reproduction and Fertility 70 235-241

Martin ICA and Watson PF (1973) The effects of dilution rate and diluent on the fertility of ram semen Journal of Reproduction and Fertility 32 310-311 
Martin ICA and Watson PF (1976) Artificial insemination of sheep: effects on fertility of number of spermatozoa inseminated and of storage of diluted semen for up to 18 hours at $5^{\circ} \mathrm{C}$ Theriogenology 5 29-35

Rothschild L (1948) The activity of ram spermatozoa Journal of Experimental Biology 25 219-226

Rothschild L (1953a) A new method of measuring the activity of spermatozoa journal of Experimental Biology $30178-199$

Rothschild L (1953b) A new method of measuring sperm speeds Nature 171 512-513

Salamon S (1976) Artificial Insemination of Sheep. Publicity Press, Chippendale NSW

Salamon S and Visser D (1972) Effect of composition of Tris-based diluent and of thawing solution on survival of ram spermatozoa frozen by the pellet method Australian Journal of Biological Science 25 605-618

Setchell BP (1991) Male reproductive organs and semen. In Reproduction in Domestic Animals pp 221-249 Eds HH Cole and PT Cupps. Academic Press, New York

Sidhu KS and Guraya SS (1990) A simple turbidimetric analysis of forward motility of buffalo bull (Bubalus bubalis) sperm Buffalo Joumal 6 69-75

Skoog DA (1985) Principles of Instrumental Analysis. Saunders College Publishing, Philadelphia

Snedecor GW and Cochran WG (1967) Statistical Methods. The lowa State University Press, lowa

Sokoloski JE, Blasco L, Storey BT and Wolf DP (1977) Turbidimetric anaiysis of human sperm motility Fertility and Sterility 28 1337-1341

Steel RGD and Torrie JH (1980) Principles and Procedures of Statistics: A Biometrical Approach. McGraw-Hill, Singapore
Steinbach J and Foote RH (1967) Osmotic pressure and pH effects on survival of frozen bovine spermatozoa Joumal of Dairy Science 50 205-213

Stewart-Savage J and Bavister BD (1988) Deterioration of stored culture media as monitored by a sperm motility bioassay Journal of In Vitro Fertilization and Embryo Transfer 5 76-80

Suttiyotin P and Thwaites CJ (1991) The ability of trypan blue to differentiate live and dead ram spermatozoa Animal Reproduction Science 25 209-224

Suttiyotin P and Thwaites CJ (1992) A comparison of a swim-up technique with the Hamilton Thorn Motility analyser for measurement of sperm velocity and motility Reproduction Fertility and Development 4, 153-160

Suttiyotin P, Sanchez-Partida LG, Thwaites CJ and Setchell BP (1991) Correlation of objective measurements of sperm motility by a swim-up technique and a modified sperm penetration test with results obtained with a Hamilton Thorn Motility Analyser Proceedings of the Australian Society of Reproductive Biology 2336

Tanphaichitr N, Lee G, Randall M, Seibel M, Fitzgerald L and Taymor M (1987) An increase in in vitro fertilization ability of low-density human sperm capacitated by multiple-tube swim-up Fertility and Sterility 48 821-827

Tso W-W and Lee W-M (1980) Seminal plasma and progressive motility of boar spermatozoa International Journal of Andrology 3 243-250

Watson PF and Martin ICA (1976) Artificial insemination of sheep: the effect of semen diluents containing egg yolk on the fertility of ram semen Theriogenology $6559-564$

Yassen AM and Foote RH (1967) Freezability of bovine spermatozoa in Trisbuffered yolk extenders containing different levels of Tris, sodium, potassium and calcium ions Journal of Dairy Science 50 887-892 